\title{
Reduciendo el uso de antibióticos en niños
}

Reducing Antiotic Use in Children: A Randomized Trial in 12 prectices. Finkelstein JA, Davis RL, Dowel SF, et al. Pediatrics. 2001; 108 $1-7$.

\section{Objetivo}

Analizar si una intervención educativa directa a médicos y familiares de niños menores de 6 años de edad, reducía la prescripción de antibióticos (ATB).

\section{Diseño}

Ensayo clínico randomizado con un análisis pre-intervención para tener información basal de la prescripción de ATB.

\section{Lugar}

Doce centros pertenecientes a dos organismos prestadores de salud gerenciados en EE.UU.

\section{Participantes}

Niños menores de 6 años.

\section{Intervención}

La intervencion fue aleatorizada en forma estratificada* de acuerdo a su tamaño y la organización a la que pertenecían. El material educativo utilizado en la intervención (profesionales de la salud y padres) fue confeccionado por el Centers for Disease Control and Prevention (CDC). Entre octubre y noviembre de 1997, expertos en el tema realizaron talleres. con pequeños grupos de médicos durante 90 minutos. Los tópicos a discutir fueron: resistencia ATB como problema general y las potenciales vías de prevención en el sobreuso de ATB; los beneficios de medicar o no las infecciones respiratorias y el diagnóstico diferencial de otitis media. En el mismo periodo los familiares recibieron por correo una carta firmada por el pediatra, con folletos y material educativo "Sus niños y los ATB". El objetivo de la intervención a familiares fue reforzar el mensaje que veían en las salas de espera y consultorios. A los 4 meses de realizados los talleres, los expertos visitaron los lugares del grupo intervención para reforzar la conducta y hacer feed-back respecto a la prescripción previa.

\section{Medición de resultados principales}

El resultado primario fue comparar la tasa de uso de ATB por persona/año, en niños de 3 meses a 3 años y de 3 a 6 años entre el grupo intervencion y el control. Realizaron ajuste según grupo de edad y según prestador de salud y analizaron si la práctica estaba relacionada con la prescripción de ATB.

\section{Resultados principales}

Hubo 8815 niños que contribuyeron con los datos en ambos años. El 62\% de los ATB utilizados fue en otitis media (OM), 6.5\% en faringitis, $6.3 \%$ en sinusitis y $9.2 \%$ en resfrío y bronquitis. La tasa ATB dispensado a niños entre 3 y 36 meses disminuyó a 0.41 ATB por persona-año (18.6\%) en el grupo intervención y 0.33 ATB por persona-año (11.5\%) en el grupo control. En los niños mayores la prescripción de ATB disminuyó a 0.21 ATB por persona-año (15\%) en el grupo intervención y 0.17 ATB por persona-año $(9.8 \%)$ en el grupo control.

\section{Otros resultados}

Al ajustar por factores confundidores* como la edad, por el año pre-intervención y por centro, se mostró que la reducción de prescripción de ATB atribuida a la intervención fue del 16\% (IC 95\% $8-23$ ) en los < de 3 años y del 12\% (IC 95\% 2-21) en niños mayores.

\section{Conclusiones}

Las intervenciones educativas focalizadas y continuas dirigidas a padres y médicos redujo el uso de antibióticos en atención primaria.

\section{Comentario}

Cada año en EE.UU. se prescriben 110 millones de ATB, especialmente en niños. Estudios previos argumentan que tienen una elevada tasa de resistencia, en particular a la penicilina 1 , que en niños es de alrededor del $41 \%$ y en adultos oscila entre $27.8 \%$ y $16 \%$. 2 Entre 1997 y 1998, la prescripción de ATB disminuyó, debido a que organismos de salud pública y el CDC realizaron campañas en todo el país mediante la prensa, publicidad y educación a profesionales de la salud 3 ; aunque es incierto que las intervenciones acotadas en el tiempo provoquen cambios de conductas. Este estudio mostró que una intervención educativa focalizada y directa (médicos, enfermeros y familiares) es eficaz, situación que nos hace pensar que los cambios pueden ser graduales y duraderos si se realizaran este tipo de intervención continuas en el tiempo. El diseño utilizado en este estudio es el adecuado, aunque los autores refieren algunos inconvenientes como no poder corroborar el diagnóstico realizado por los médicos ya que los datos de prescripción de ATB se obtuvieron de las bases de datos de las farmacias proveedoras del sistema médico gerenciado. Tampoco pudieron discriminar los ATB utilizados como profilaxis en $\mathrm{OM}$ e infección urinaria. Respecto a este punto los investigadores comentan que en la tasa de prescripción global de ATB, la contribución de la profilaxis seguramente es mínima. En cuanto a que las OM ocasionaron la mayor tasa de prescripción los autores argumentan que es posible que exista un sobrediagnóstico, pero que al no poder corroborarlo solo es una presunción. Para finalizar, pensamos que la educación dirigida a los padres acerca de la historia natural de las enfermedades virales y en especial las respiratorias que ocasionan el mayor uso de ATB, puede cambiar la presión que muchas veces ellos ejercen en los médicos para recetar ATB, situación vivida por muchos de nosotros en nuestra práctica diaria.

Dra. Nanci Giraudo [ Unidad de Medicina Familiar y Preventiva. Hospital Italiano de Buenos Aires ]

1. McCaig LF, Hughes JM. Trends in antimicrobial drug prescribing among office-based physicians in the Unites States. JAMA. 1995; 273: 214-219. 